\title{
Processing developments in employee performance and reward
}

\author{
Stephen J. Perkins \\ London Metropolitan University, London, UK
}

\begin{abstract}
Purpose - The purpose of this paper is to surface and discuss issues associated with employee performance appraisal as a multi-staged social interaction reportedly the butt of managerial dissatisfaction, especially when used to inform decisions around pay and other rewards.

Design/methodology/approach - To substantiate the territory, existing management-based evidence from the published literature is curated and discussed to frame issues for investigation under the rubric of performance appraisal as an activity that may be understood as combining interaction between forms of administrative, social and psychologically oriented control. Primary evidence, drawn from recent research sponsored by the Chartered Institute of Personnel and Development, which combines data sets informed by a survey of HR specialists and a follow-on focus group, is then used to illustrate views on relevant themes across a sample of UK-based private, public and third sector organizations $(n=715)$.

Findings - A significant number of organizations apply performance appraisal approaches, somewhat mediated by sector and size, and in turn use the results to inform various forms of HRM decision making - in particular reward management. While claims have been circulating in popular media suggesting the widespread abandonment of traditional performance appraisal, and while the study finds dissatisfaction regarding the utility of existing bureaucratic elements of appraisal mechanisms, the position is more nuanced. Practical implications - Corporate management attention is drawn to choices of the extent to which they are investing in building line management capabilities to address the consequences of policy decisions to amplify the importance of informal alongside formal performance management processes, and potential reward decision making, mindful of the indeterminate character of the employment relationship and its dynamic, socially constructed character.

Social implications - Performance appraisal may benefit from re-interpreting the balance between emphasis on administrative, social and self-control, given changing expectations among workforce members and those who evaluate organizational effectiveness in contemporary society, and the ongoing contested nature of organizational control.

Originality/value - Employee performance appraisal as an institutional process central to organizational control systems is a topic of interest to both organizational effectiveness academics and the managerial practitioners they study. Using data that broadly represent recent developments in managerial practice across "UK plc", the paper informs reflection on theory and practice.
\end{abstract}

Keywords Performance appraisal, Psychological contract, Process, Social exchange, Management control, Reward management

Paper type Research paper

\section{Introduction}

It has been reported that "There has been much debate over and criticism of performance appraisal recently" (CIPD, 2017). There are claims that performance appraisal and associated pay determination are changing radically (e.g. Cappelli and Tavis, 2016). Instances have been cited of employers abandoning ratings for individual employee appraisal outcomes. In the USA, prominent examples include Accenture, Adobe, Deloitte, GAP, GE Medtronic and Microsoft (van Ophem, 2017). Recent UK primary research evidence informing this paper however suggests a need for more nuanced consideration of the issue and action on it.

The author wishes to acknowledge the input of Dr Marie Bailey and Liz Marriott in assembling the empirical data informing this paper.

Employee performance and reward 
The socially constructed nature of performance appraisal means that employers can reconstruct, or change, it. But its social character implies that, while organizations may seek to harness it as part of their managerial control systems (Langfield-Smith, 2007), given the indeterminate nature of the employment relationship (Marsden, 1999) it is risky to assume that capacity to change in ways that contribute to organizational effectiveness is exclusively regulated by corporate and/or front-line managers. The latter, in their role as supervisors of employee performance and its appraisal do however play a "pivotal": role Kavanagh, et al. (2007, p. 136), suggesting the need for corporate management attention to this element in the process of managing performance, and its recognition such as through pay awards.

Rather than abandoning orthodoxy in performance appraisal and pay setting rituals (Islam and Zyphur, 2009), whether or not that process involves ratings, and given the symbolic as well as practical significance of such "ceremonial rites" (op. cit.), it may benefit organizations to move on from what Lawler (1997) (author's personal notes) once described as "an annual rain dance". Instead to evolve the process into a continuing dialogue between employees and those who supervise their work. The development is not insignificant; it carries important consequences for the extent and quality of managerial skills, and for the role of HR functions in supporting line managers in their interactions with workforce members.

Questions for research informing this paper are:

(1) How may performance appraisal and its links with employee reward management be specified as a socio-psychological, not just an economic, exchange process?

(2) What can we learn, to inform further investigation and organizational effectiveness initiatives, from discussion of views on current practice in this area gathered from among UK-based human resource management specialists?

The paper continues with a discussion of relevant literature to help frame performance appraisal as an institutionalized social process channeling managerial aspirations to control the interaction with workforce members, mediated through the supervisors who appraise them. Following a brief description of methods, it then presents findings from recent primary research intended to surface how organizations are engaging managerially with performance appraisal and in particular employee reward management decisions consequent on it, before identifying propositions that may usefully inform future research and managerial practice.

\section{Literature review}

Kavanagh et al. (2007) encourage analytical focus on the process of performance appraisal, through combining ideas from process theory and social exchange theory. Process theory (Van De Ven and Poole, 1995) guides understanding of how change occurs - for example, influencing the way an employee performs in accordance with specific criteria negotiated with their supervisor, and then receives some form of recognition for the outcome. Cooperation with institutionalized change processes, i.e. those that have been become embedded and recognized, possibly taken for granted, in the workings of an organization (Zucker, 1987), may depend on the degree to which the parties perceive it in their interests to do so.

From an employer's standpoint institutionalized organizational features been characterized, along one dimension as externally imposed coercion to act in particular ways (e.g. compliance with legal regulation such as ensuring performance appraisal processes do not discriminate against certain "protected characteristics" of demography such as ethnicity or gender). Along another dimension there are "mimetic" features - adoption of arrangements viewed as having been successful elsewhere and when uncertain of alternatives (e.g. to ensure regulatory compliant performance appraisal processes). Along a third dimension, operational standards may often be mediated via professionals (e.g. Chartered CIPD members following professional body endorsed criteria for performance appraisal and its attendant outcomes), in the form of "normative transmission of social facts" (Zucker, 1987, p. 444). 
Interaction between humans is a dynamic process influenced by the relationships between the parties, informed by emotional considerations, in turn, reflecting the cultural context for the interaction (Marinetti et al., 2011). Managerial approaches to performance appraisal, with a view to arriving at a perspective on employees' value potential and results achievements may benefit from attention to the interactants' autonomy, desires, intentions and interests (Kincaid, 2012). Then there is a question as to the degree of homogeneity among the interactants (Saleh et al., 2005). Do they have similar educational profiles, for example, influencing the ways in which they engage in interpersonal communication and meaning formation? Or a common sense of what value ought to be attached to particular capability and performance levels? Positive interpersonal relations, for example, reduce economic transactional costs, and affect wellbeing of the actors involved (Gui and Sugden, 2009). And, especially relevant for the topic of this paper, "incentive, consultation and monitoring arrangements affect relations among peers and between superiors and inferiors within enterprises [...] and may promote or hinder the creation and maintenance of patterns of collaboration among [organization] members" (op. cit: 5).

From the employee's standpoint, an important consideration will be whether or not the processes are viewed as fair or just - i.e. extending beyond a purely economic frame of reference. A consideration here according to Kavanagh et al. (2007) is the degree to which an individual feels in control of the process (thus positioning themselves in relation to another social actor), with control enabling a process to bring about outcomes favorable to the individual. An employment relationship and associated performance appraisal processes involve the interplay of managerial control efforts to secure managerially desired outcomes, and the aspirations of employees whose cooperation cannot be taken for granted. Kavanagh et al. (2007) therefore introduce the notion of social exchange - alongside the economic exchange inherent in an employment contract - to encourage attention to underlying expectations between the parties as to reciprocity and fair play that mediate the degree to which an employee will take a risk that, if they cooperate with demands on their performance by a supervisor, then the supervisor will embrace a reciprocal sense of obligation at some future point in time to recognize and value the contribution the employee has made.

Organizational justice theory (Brown et al., 2010) may be applied to assist interpretation, combined with psychological contract theory. The latter helps describe the basis on which individuals will judge fairness in their experience of the performance appraisal process not only through tangible conditions being applied but through communication (Guest, 2006) of one or more unwritten aspects of a performance appraisal and recognition process that, given the dynamic nature of organizational processes (Rousseau et al., 2018), may be difficult or impossible to codify and document in advance. It may be inferred that organizational justice needs to be seen to be achieved not only in terms of the outcomes from performance appraisal, say, when an individual makes a comparison between their goals and recognition for achieving (or sanction for falling short) they receive in comparison to other workforce members they tend to benchmark themselves against. It also depends on the degree to which the employee senses justice or its absence in the operation of the performance appraisal process - exemplified in the degree of control they can exercise, at least in having sufficient information to influence inputs to and outputs from it. And organizational justice theory signifies also the need for an employee to sense fairness in the interpersonal aspects involved: is the quality of relationship with their supervisor (performance appraiser) one they feel confident will lead to reciprocal exchange of benefit so that they will trust the process and the people and then cooperate to help secure organizational priorities (Shortland and Perkins, 2016)?

Returning to the managerial point of view, taking the foregoing observations into account, it may be further inferred that successful efforts to control performance appraisal will require attention to more than mechanistic application of an administrative process. Hopwood's classic model for interpreting management control systems describes the 
complementary and dynamic interplay between three elements: administrative control, social control and self-control (Hopwood, 1976). Management control was defined by Anthony (1965) straightforwardly as representing the process to ensure organizational objectives are effectively and efficiently accomplished through obtaining and using resources intended for that purpose.

Administrative, or impersonal bureaucratic controls might be manifested in performance appraisal by an emphasis on measurable outputs to be achieved in the way number of sales, for example, may be positioned, possibly connected with an economic incentive for an individual to achieve them by the prospect of receiving a commission or bonus payment. However, given the dynamism of organizational settings and difficulty in applying controls able to scrutinize every action an employee may take - or may withhold - in performing their role, scope is opened up for discretionary effort by an individual working singly or as part of a team that may assist or harm attainment of managerial priorities. As Rousseau et al. (2018) argue, functions of processes associated with the psychological contract between employee and supervisor involve promises, inducements, contributions and obligations that evolve in a phased manner.

Thus socially constructed, continuously negotiated, processes between the dyads and wider groupings of managers and employees at work give rise to interconnected stages of explicit and implicit exchange which under Hopwood's (1976) model may be positioned in terms of social controls. Factors that the ritualized processes of performance appraisal (and possible subsequent recognition) enable managers to complement administratively oriented signals to their subordinates with those communicating norms and values they hope to socialize employees into embracing by way of a normative commitment. The latter mediated by psychological contract expectations individuals bring from outside a specific employment relationship. Including a sense of obligation to reciprocate permitted entry to the employing organization in exchanges with their managers (Delobbe et al., 2016), by becoming embedded with peers and other organization members in a shared enterprise, including how they approach the process of performance appraisal. Put another way, conformity with what Ouchi (1979) terms "clan control."

Given the choice as to whether or not discretionary effort to attain performance outcomes specified for them managerially is something an employee wishes to invest in, having weighed up the risk of whether or not this will result in creating a reciprocal obligation on the supervisor's part, a further element in the interconnecting aspects of the management control process may be introduced to consolidate the socialization process (Hopwood, 1976). Given the indeterminate nature of the employment relationship, the more an individual acts in ways that demonstrate self-control, regulating their behavior matched to managerial constructions of what will advance organizationally effective outcomes, the greater confidence corporate management, and those who in turn appraise their performance, may perceive they have in securing value from investment in particular human resources.

It may be reasoned that these dynamic, socially constructed interconnections, if a sense of reciprocal commitment is to be negotiated through performance appraisal processes, create conditions in which front-line management supervision will require considerable finesse and skill. What do managerial control, social exchange and organizational justice process considerations imply then for understanding the specific characteristics of performance appraisal and outcomes supervisor/appraisers need to engage with?

The traditional performance appraisal process has been constituted in the academic literature as combining three stages (Storey and Sisson, 1993). First, there is an objective setting stage, guiding an employee in applying their skills and effort to the benefit of the organization. Second, a feedback stage in theory involving regular communication with their supervisor on how they are doing in progression toward the intended objectives. 
And third, there is an evaluation by the supervisor (perhaps submitted for "grandfathering" up the line either by the appraiser's own line manager or by a management committee) which arrives at a view, conventionally an enumerated rating, of performance across the entire cycle since the objective setting stage. This rating then may be translated into adjustments to pay - whether salary or bonuses (Brown and Benson, 2005).

Questions arise for management practice in undertaking employee performance appraisal, derived from relevant social science reasoning. At the first stage, for example, Locke and Latham's (1990) goal setting theory encourages appraiser-supervisors to set specific, challenging but achievable goals (Milkovich and Newman, 2002) that impact positively on the appraisee's psychological state. They are to be "arousal producing" (Taylor and Pierce, 1999, p. 424). But the quality of the social interaction between supervisor and staff member is key: specificity is important if the outcome is to be increased effort leading to individual contributions to organizationally effective success. Specificity, using the terms Milkovich and Newman (2002) prescribe for it, to act in support of managerial intentions in an indeterminate relationship with the employee, needs to be seen to be fair. In this case fair in the sense that an employee will feel justly served by the interpersonal interaction itself and the accompanying corporately designated process as well as in terms of anticipated outcomes. "Organizational justice" principles as summarized in the preceding section serve as a socially significant thread throughout every stage of the performance appraisal process.

Also, as Brown and Benson (2005) argue, care is needed in setting performance objectives to avoid a situation where overload and stress set in, undermining the positive reaction to the relationship between employee goal setting and performance demonstrated in "a sizable body of research" (p. 102). Significant skill on the part of managers is required, therefore, in getting the goal setting right so that performance appraisal-informed control systems are effective. Bearing in mind that any individual manager is probably supervising the performance of a number of employees who, if not deployed in ways that balance the demands for management control with individual psychological contracts, may seek to achieve performance and its recognition in ways that are counterproductive. The process itself is further complicated by arguments that to be successful it is important that, in setting performance objectives, dialogue is multidirectional: so, the parties need scope to comment and potentially question managerial interventions, in turn, yet further complicated when performance appraisal needs to occur in ways that provide meaningful involvement for a multiplicity of interests.

These reflections surface the question of the extent to which managers charged with supervising performance appraisal are satisfied with the processes they must follow across varying organizational contexts constraining or enabling codification. And demands on them to secure organizational effective outcomes from resources delegated to them, mindful of diverse employee characteristics and expectations. Relatedly, confidence in the level of support from corporate management to ensure their competence to discharge their function as a performance appraiser.

A manager's role in the second stage of performance appraisal is also one of managing effective two-way communication (and then enjoining this seamlessly across all appraisees). At least one formal feedback session has traditionally applied, complemented by informal appraiser-appraisee communication sessions to provide feedback over the course of a particular performance appraisal cycle (Cardy and Dobbins, 1994). According to Landy et al. (1982), a body of research has been published indicating that feedback is critical if employees are to improve their performance. And a subsidiary benefit claimed is that, just as in spelling out what employees are to achieve, describing through continuous feedback how this is to be achieved, as the performance is still evolving, enhances not only the commitment to achieve the intended performance outcomes but also to the organization itself.

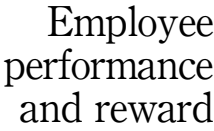


A problem found in the literature on performance feedback is that employees are fearful of it, in the expectation that appraisers will accent negative over positive outcomes and use the opportunity to load on further work pressure (Brown and Benson, 2005), leading Lewis (1998) to conclude that feedback during any given appraisal cycle is the most neglected aspect. Managers too have been adjudged reluctant given the possible exposure to employee agency to secure clarity around "the rules of the game" fearing they may choose to act opportunistically. To concentrate on aspects leading to favorable performance ratings while downplaying attention to other factors that may be of equal importance to the organization - in other words ceding some control over the process to employees (Taylor et al., 1997).

CIPD (2016) guidance emphasizes attention to quality of the process of feeding back to employees on their performance given the interaction with employee expectations, whether this is to inform pay reviews or for career development planning. If not properly managed, gaps between expectations and outcomes may give rise to negative emotions that distract attention from continuous performance improvement. Operating counterintuitively to the connections postulated in mainstream theory between giving clear managerial feedback and enhancing employee performance. Again, then there is a significant area of risk that an individual manger's capacity to oversee effective performance appraisal will be exposed, due to other organizational constraints (e.g. competing demands on a supervisor's time), with negative effects reinforced if a manager's capacity to balance clarity, firmness and sensitivity to individual reactions falls short. Adding to the potential areas for dissatisfaction on the part of managers and implications for corporate management action to address it, if effective performance appraisal is not to be confounded.

At the third - evaluation - stage of performance appraisal, managers with responsibility for subordinate appraisals identify and rate performance, with potential consequences for another administrative decision, namely, recognizing and rewarding individuals (and possibly groups of employees) contingent on the rating level awarded. Questions arise here not only around the administrative process, but on considerations of perceived equity - or often inequity (Adams, 1963). Given its indeterminate nature, the aim for the relationship between employee and employer (or their proxy in the form of a professional line manager) is to direct and if necessary change employee behavior to meet organizational priorities. To overcome the risk that employees may withhold cooperation if grounds for committing to reciprocal exchange are lacking, appraisers face the need dynamically to create, maintain and repair explicit and implicit exchange relations where their appraisees trust them to do the right thing in making judgments about performance that will not only be organizationally efficient but achieve an acceptable psychological contract with employees (Rousseau et al., 2018). One in which the outcome, the process and its operation, and the interpersonal interaction itself are deemed fair by individuals in comparison with peers and generally across the organization.

The evaluation and possible rating stage of performance appraisal is important then not only in respect of administrative (HRM) outcomes. It also impacts for good or bad on the individual's sense of self-esteem, given the outcome of appraisal is an express statement by management of their view of an employee's worth - revealing both the tangible and symbolic elements of the performance rating ritual intended to incorporate the individual into a larger social entity (Islam and Zyphur, 2009). The consequences of which are reinforced by research indicative that employees tend to rate themselves more generously than those who appraise them, including peer-raters, with less variability between ratings levels (Solomonson and Lance, 1997), further challenging managers effectively to manage expectations. At a purely functional level, recent commentary suggests decisive action here explains why particular management styles lead to distinctive business outcomes (Bloom et al., 2011): profit levels, corporate growth rate, share price, and sustainability. 
Comparing managerial practice between the USA and other countries, the findings are indicative of an American management style that rewards and promotes speedily when good performance is assessed; and at the same time initiates retraining or dismissals of employees at a similar pace due to an institutional setting providing mangers with access to more "at will" (or hire and fire) employment contract conditions. The stakes are thus high, giving managers possible cause for concern as to the challenge before them in securing organizationally effective outcomes from the employee performance appraisal process.

\section{Methods}

Analysis in this paper draws on data assembled to inform the 2017 Annual Reward Survey published by the Chartered Institute of Personnel and Development (Bailey et al., 2017). This data set includes 715 responses to an online questionnaire completed by HRM practitioners in late spring 2017 complemented by a workshop discussion of preliminary findings in summer 2017 involving a dozen senior HR (reward) management specialists representing private- and public-sector organizations.

Survey respondents were asked to declare whether or not they operated financial or non-financial performance related reward arrangements, and if so what kinds of arrangements applied. Respondents were asked to declare their practices in respect of managing individual performance, both goal setting and providing feedback on assessed performance. Responses were to include reference to the use or absence of performance ratings, and the basis on which these might be awarded - absolute or relative to peers. Further information was solicited covering encouragement to managers, or its absence, to check back with employees to understand their views on process as well as outcomes for performance assessments applicable to them. Demographic information was collected to understand the character of the employing organization: sector, size, ownership (domestic or international). Survey respondents were also invited to comment on business and HRM strategy considerations, and the perceived impact of external factors (e.g. economic, legal and other regulatory phenomena).

\section{Findings}

The survey results indicate that two thirds of organizations (66 percent) have regular discussion of employees' performance. In half of those cases appraisal feedback informs salary decisions (31 percent of all organizations), and in 21 percent of organizations these feedback discussions inform other reward decisions (Table I).

Only 36 percent of organizations report their management as satisfied with the level of feedback provided to employees following performance appraisals. This carries consequences in terms of overall communication between management and employees regarding what they are expected to do in performing their roles and how they are perceived as doing it. Consequences for employee motivation may be inferred from this finding, reinforced by the fact that in 27 percent of organizations employees are aware that feedback informs salary/reward decisions.

$\%$ of respondents

Regular discussion of employee's performance

Organization satisfied with level of feedback provided
Employee performance and reward 
Public and voluntary sector organizations are most likely to have regular discussions of performance but are not noticeably more likely to use these for salary decisions and much less likely to use them for other reward decisions. Private sector services companies are most likely to use them to inform both salary and other reward decisions. In terms of significant correlations between organizational size and reported practice, very large organizations are most likely to hold discussions but least likely to be satisfied with feedback provided. Very large organizations are also more likely to use discussions as basis for both salary and other reward. However, the distinction between SMEs and large organizations is not so clearly defined, with mixed figures. Although level of satisfaction with level of feedback diminishes with organization size. And in terms of strategic orientation, while those organizations whose focus is "innovating to increase productivity" are most likely to have regular discussions of performance, it is those whose focus is "enhancing value for money" which are most likely to use those discussions to inform salary decisions.

What is going on that might help illuminate these descriptive statistical results? When the findings were put to a focus group of senior reward management practitioners, against a backdrop of the discussion within the wider HRM community on the value of the performance appraisal process and its role in determining reward, diverging viewpoints surfaced.

For some specialist practitioners, the performance appraisal process attracts criticism from line managers who believe that the return on investment is poor, in terms of managerial effort to complete them vs the marginal increases in pay levels and consequent impact on incentivising and recognizing employees. One observer described the process as akin to "moving grains of sand". However, for others, the process forms a necessary part of people management and the role of the performance appraisal process is increasing, not reducing.

While the survey data show ongoing commitment among a significant proportion of employers to performance appraisal, in discussion, the practitioner panel reported moves toward loosening the relationship between pay and performance. Some panelists commented that, in their own sectors, organizations are still linking variable pay, but not determination of base rate, to performance. There are also signs that organizations are moving away from individual performance ratings with an indicative trend toward more group-based incentive schemes and also developing longer-term employee recognition plans.

Perhaps the biggest change that the panel unpacked in discussing the survey data was around the performance appraisal process itself. In many cases, organizations are moving away from traditional annual and interim appraisals and toward more informal and more regular one to one dialogue between employees and their line managers. This is regarded as a much more effective approach that helps boost good and manages unacceptable performance. Panel members also saw this as a more appropriate mechanism for younger workers, who they said prefer immediate feedback on their work.

Overwhelmingly participants voiced concerns about the complexity surrounding dynamic social interaction processes related to performance appraisal and voiced the opinion that there are material consequences for front-line managerial skill sets. An approach that engages more informally and more regularly in an empathetic manner with the workforce relies heavily on the "softer" skills of line management. The importance of strong and effective line management was deemed essential for ensuring performance and pay is accurately calibrated, aligned to the value employees potentially bring to their employer, the outcomes for so that the business of applying such capabilities and, completing the performance-reward ritual, that employees are satisfied with the process. Focus group members said they recognized that investment in enhancing line management capability, and attendant specialist support in navigating the complexity of the performance appraisal process, was required to achieve organization effectiveness in this dynamic area of management. 
Discussion of issues arising to inform further research and managerial practice

Evidence from the UK sample reported on above suggests that performance appraisal processes are not working as intended, leading in some cases to calls for radical recasting of them. Disquiet among those reporting ongoing adherence to traditional ritualized, feedback-oriented performance appraisal (even if reward determination is not a direct outcome) seems heightened the larger the organizational setting. However, a deeper reading informed by ideas from the social science literature suggests that espoused changes may only address one element of a multi-staged process that is complicated by its social and psychological character. Performance appraisal represents a dynamic exercise in constructing shared meaning, though micro-level socio-psychological interactions between managers and employees that occur within wider institutional contexts. Leading to outcomes that signify as well as make tangible judgments about the value attached to individuals, which need to be justified given their impact on the character of an indeterminate employment relationship. Skillful application of the performance appraisal process is needed, even when employees are predisposed to cooperate with managers. Intended management control mediated through the process of performance appraisal extends beyond its administrative boundaries opening up the locus of control to possible contestation if the process, not simply the outcome, breaches tests of fairness and the psychological contract.

Corporate management attention, informed by more socially aware research addressing the micro interactions between dyads and other performance appraisal pairings, may be usefully directed to consider diffused control systems that respect the indeterminate nature of the relationship between the parties and prioritizing support for line managers involved in the appraisal of those accountable to them that builds greater capacity for handling the consequences of that indeterminacy while accommodating institutional requirements.

A number of propositions may be induced from the analysis in this paper confronting evidence of organizational viewpoints with relevant ideas from the social science literature:

P1. As a dynamic, multi-staged process the ritual of performance appraisal, with both practical and symbolic consequences, needs to be approached as a negotiated micro-level social exchange whose outcome is indeterminate, but with potential for managers to convert an employee's predisposition to cooperate provided they can achieve balance in controlling it fairly to realize reciprocal benefits.

$P 2$. Greater scale of organizational resources may result in more bureaucracy around attempts to control the performance appraisal process, opening up a sense of distance between the parties, in turn, increasing managerial dissatisfaction due to extra-organizational institutional constraints on their capacity to act meaningfully on judgments to recognize or penalize individual contributions.

P3. Prescription, mediated through normative "professionalised" channels, on the performance appraisal process has over-emphasized the administrative over other aspects, overlooking the indeterminacy of the social and psychological relations in play.

P4. Managers feel constrained by coercive institutional factors, leaving them wanting to reject ritualized performance appraisal, and that they lack capability or confidence to risk sharing control over the process with those they supervise, and have to justify process stages and outcomes to interpersonally.

P5. Corporate managements who sustain an organizationally effective performance appraisal process invest in developing line management capacity to cope with the social and psychological as well as administrative aspects of performance appraisal,

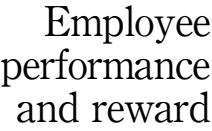


as well as empowering line managers who in turn empower their employees individually and in groups to align perceptions of performance levels, and the recognition they deserve absolutely and relatively as appraisal rituals play out across localized "clan" settings, as well as agility in following through with forms of reward and sanction overcoming external constraints on this capacity.

\section{Conclusion}

Organizational effectiveness of performance and reward management processes may be judged managerially in terms of securing and maintaining control to meet corporate priorities, and also by employees weighing up the degree to which they will cooperate with supervisors' efforts to specify and appraise their performance on the promise of reciprocal socio-economic justice. Empirical findings in this paper are limited to cross-section samples of UK HR specialists assembled using mixed methods. Future research might be designed to widen the population whose views are sought to include line managers and groups of employees who participate in the process of performance appraisal, building on theoretical knowledge around the character and dynamics of micro-level social interaction for which symbolic interactionist and ethnomethodological approaches (e.g. Blumer, 1969; Garfinkel, 1967) have long offered systematic pathways to engage with rich, qualitative data. Paying particular attention to the procedural and interpersonal elements of performance appraisal and reward, looking beyond the albeit important distributional justice considerations.

\section{References}

Adams, S.J. (1963), "Towards an understanding of inequity", Journal of Abnormal and Social Psychology, Vol. 67 No. 5, pp. 422-436.

Anthony, R.N. (1965), Planning and Control Systems: A Framework for Analysis, Harvard University Press, Cambridge MA.

Bailey, M., Mariott, L. and Perkins, S.J. (2017), Annual Reward Survey, CIPD, London.

Bloom, N., Homkes, R., Sadun, R. and Van Reenen, J. (2011), "Why American management rules the world”, Harvard Business Review, June 13, available at: https:/hbr.org/2011/06/why-americanmanagement-rules

Blumer, H. (1969), Symbolic Interactionism: Perspective and Method, Prentice-Hall, NJ.

Brown, G., Bemmels, B. and Barclay, L.J. (2010), "The importance of policy in perceptions of organizational justice”, Human Relations, Vol. 63 No. 10, pp. 1587-1609.

Brown, M. and Benson, J. (2005), "Managing to overload?: work overload and performance appraisal processes", Group Organization Management, Vol. 30 No. 1, pp. 99-124.

Cappelli, P. and Tavis, A. (2016), "The performance management revolution", Harvard Business Review, October, pp. 58-67, available at: https://hbr.org/2016/10/the-performance-managementrevolution (accessed October 12, 2017).

Cardy, R.L. and Dobbins, G.H. (1994), Performance Appraisal: Alternative Perspectives, South Western Publishing, Cincinnati, $\mathrm{OH}$.

CIPD (2016), "Rapid evidence assessment of the research literature on the effect of performance appraisal on workplace performance", Technical Report, CIPD, London.

CIPD (2017), "Factsheet - performance appraisal: understand the basics of performance appraisals and how to ensure the process adds value to the organization", available at: www.cipd.co.uk/ knowledge/fundamentals/people/performance/appraisals-factsheet (accessed August 8, 2017).

Delobbe, N., Cooper-Thomas, H.D. and De Hoe, R. (2016), "A new look at the psychological contract during organizational socialization: the role of newcomers' obligations at entry", Journal of Organizational Behavior, Vol. 37 No. 6, pp. 845-867. 
Garfinkel, H. (1967), Studies in Ethnomethodology, Prentice-Hall, NJ.

Guest, D.E. (2006), "Communicating the psychological contract: an employer perspective", Human Resource Management Journal, Vol. 12 No. 2, pp. 22-38.

Gui, B. and Sugden, R. (2009), "Why interpersonal relations matter for economics", in Gui, B. and Sugden, R. (Eds), Economics and Social Interaction: Accounting for Interpersonal Relations, Cambridge University Press, Cambridge, pp. 1-22.

Hopwood, A.G. (1976), Accounting and Human Behavior, Prentice-Hall, Englewood Cliffs, NJ.

Islam, G. and Zyphur, M.J. (2009), "Rituals in organizations: a review and expansion of current theory", Group and Organization Management, Vol. 34 No. 1, pp. 114-139.

Kavanagh, P., Benson, J. and Brown, M. (2007), “Understanding performance appraisal fairness”, Asia Pacific Journal of Human Resources, Vol. 45 No. 2, pp. 132-150.

Kincaid, H. (Ed.) (2012), Oxford Handbooks. The Oxford Handbook of Philosophy of Social Science, Oxford University Press, Oxford.

Landy, F.J., Farr, J.L. and Jacobs, R.R. (1982), "Utility concepts in performance measurement", Organizational Behavior and Human Performance, Vol. 30 No. 1, pp. 15-40.

Langfield-Smith, K. (2007), "A review of quantitative research in management control systems and strategy", in Chapman, C.S., Hopwood, A.G. and Shields, M.D. (Eds), Handbook of Management Accounting Research, Vol. 2, Elsivier, London, pp. 753-783.

Lawler, E.E. III (1997), SRRC Masterclass: 'Strategic Pay' - Author Notes, Strategic Remuneration Research Centre, London.

Lewis, P. (1998), "Managing performance related pay based on evidence from the financial services sector", Human Resource Management Journal, Vol. 8 No. 2, pp. 66-77.

Locke, E.A. and Latham, G.P. (1990), The Theory of Goal Setting and Task Performance, Prentice Hall, Englewood Cliffs, NJ.

Marinetti, C., Moore, P., Lucas, P. and Parkinson, B. (2011), "Emotions in social interactions: unfolding emotional experience", in Cowie, R., Pelachaud, C. and Petta, P. (Eds), Cognitive Technologies. Emotion-Oriented Systems, Springer, Berlin, pp. 31-46.

Marsden, D. (1999), A Theory of Employment Systems, Oxford University Press, Oxford.

Milkovich, G.T. and Newman, J.M. (2002), Compensation, 7th ed., McGraw-Hill Irwin, Boston, MA.

Ouchi, W.G. (1979), "A conceptual framework for the design of organizational control mechanisms", Management Science, Vol. 25 No. 9, pp. 833-849.

Rousseau, D.M., Hansen, S.D. and Tomprou, M. (2018), "A dynamic phase model of psychological contract processes", Journal of Organizational Behavior, pp. 1-18, available at: https:// onlinelibrary.wiley.com/doi/abs/10.1002/job.2284?af=R

Saleh, M., Lazonder, A. and De Jong, T. (2005), "Effects of within-class ability grouping on social interaction, achievement, and motivation", Instructional Science, Vol. 33 No. 2, pp. 105-119.

Shortland, S.M. and Perkins, S.J. (2016), "Long-term assignment reward (dis)satisfaction outcomes: hearing women's voices”, Journal of Global Mobility, Vol. 4 No. 2, pp. 1-27.

Solomonson, A.L. and Lance, C.E. (1997), "Examination of the relationship between true halo and halo error in performance ratings", Journal of Applied Psychology, Vol. 82 No. 5, pp. 665-674.

Storey, J. and Sisson, K. (1993), Managing Human Resources and Industrial Relations, The Open University Press, Buckingham.

Taylor, P.J. and Pierce, J.L. (1999), "Effects of introducing a performance management system on employees' subsequent attitudes and effort", Public Personnel Management, Vol. 28 No. 3, pp. $423-452$.

Taylor, S.E., Repetti, R.L. and Seeman, T. (1997), "Health psychology: what is an unhealthy environment and how does it get under the skin?”, Annual Review of Psychology, Vol. 48, pp. 411-447. 
Van De Ven, A.H. and Poole, M.S. (1995), "Explaining development and change in organizations", Academy of Management Review, Vol. 20 No. 3, pp. 510-540.

van Ophem, V. (2017), "De-hyping the hype: performance ratings make the world go 'round'”, World at Work Compensation Focus, December, available at: www.worldatwork.org/adimComment?id= 82065 (accessed December 13, 2017).

Zucker, L.G. (1987), "Institutional theories of organization”, Annual Review of Sociology, Vol. 13, pp. $443-464$.

\section{Corresponding author}

Stephen J. Perkins can be contacted at: s.perkins@1ondonmet.ac.uk 